\title{
QUALIDADE DAÁGUA DE POÇOS PARTICULARES DO MUNICÍPIO DE ENCANTADO, VALE DO TAQUARI-RS
}

\author{
Jaqueline De Bortoli ${ }^{1}$, Jaqueline Fernandes Tonetto ${ }^{2}$, Maicon Toldi ${ }^{3}$, \\ Cristian Mateus Zerwes ${ }^{4}$, Mariela Inês Secchi ${ }^{5}$, Thanabi Bellenzier Calderan ${ }^{6}$, \\ Eniz Conceição de Oliveira ${ }^{7}$, Eduardo Rodrigo Ramos de Santana ${ }^{8}$
}

\begin{abstract}
Resumo: No meio rural e em áreas onde não há abastecimento de rede pública, devido ao baixo custo e facilidade de perfuração, a captação de água provêm do aquífero livre, embora possa estar vulnerável à contaminação, o abastecimento de água é feito através da utilização de poços rasos ou nascentes. $\mathrm{O}$ estudo objetivou analisar a qualidade físico-química e microbiológica da água de 10 poços próprios em um município pertencente à região do Vale do Taquari-RS. Foram coletadas amostras de água dos poços próprios, seguidos de análises físico-químicas: $\mathrm{pH}$, turbidez, cor, oxigênio dissolvido, dureza total e microbiológicas: coliformes termotolerantes $(E$. coli). Os resultados foram comparados às legislações vigentes e apontaram presença de Escherichia coli em todas as amostras analisadas. O parâmetro turbidez (80\%) e cor (50\%) estiveram acima do valor permitido pela legislação e o oxigênio dissolvido (10\%) abaixo do permitido. Concluiu-se que as águas analisadas estão impróprias para o consumo humano, os poços devem estar ter proteções físicas, passar por processo de desinfecção com uso de cloro e realizar monitoramento periodicamente.
\end{abstract}

Palavras-chave: Poços. Coliformes. Recurso hídrico. Potabilidade.

1 Doutoranda em Manejo e Conservação do Solo e da Água, Universidade Federal de Pelotas. Mestra em Ambiente e Desenvolvimento - Univates, Bióloga. jbortoli@universo.univates.br

2 Doutoranda em Agronegócios, Universidade Federal do Rio Grande do Sul, Mestra em Ambiente e Desenvolvimento - Univates, Bióloga. jaquetonetto@gmail.com

3 Doutorando em Ambiente e Desenvolvimento, Centro Universitário Univates. Mestre em Ambiente e Desenvolvimento Univates, Biólogo. maicont@universo.univates.br

4 Mestre em Ambiente e Desenvolvimento - Univates, Biólogo. cristianzerwes@gmail.com

5 Doutoranda e Mestra em Ambiente e Desenvolvimento Univates, Biológa. mariela.secchi@hotmail.com

6 Mestre em Ambiente e Desenvolvimento Univates, Bacharel em Direito. calderanadv@net11.com.br

7 Doutora em Química, Pesquisadora e Docente do Programa de Pós-Graduação em Ambiente e Desenvolvimento Univates. eniz@univates.br

8 Doutor em Engenharia de Minas, Metalúrgica e de Materiais. Analista Ambiental na Fundação de Proteção Ambiental (FEPAM). errsantana@gmail.com 


\title{
WATER QUALITY OF PRIVATE WELLS IN THE ENCANTADO CITY, TAQUARI VALE-RS
}

\begin{abstract}
In rural areas and in locations where there is no public water treatment, due to the low cost and ease of drilling, water collection comes from the unconfined aquifer, although it may be vulnerable to contamination, the water supply is made through the use of wells Shallow or springs. The study aimed to analyze the physical-chemical and microbiological quality of the water of 10 own wells in a municipality belonging to the Vale do Taquari-RS region. Water samples were collected from the wells, followed by physical and chemical analyzes: $\mathrm{pH}$, turbidity, color, dissolved oxygen, total hardness and microbiological: thermotolerant coliforms (E. coli). The results were compared to the current legislation and indicated the presence of Escherichia coli in all samples analyzed. The parameter turbidity (80\%) and color $(50 \%)$ were above the limit allowed by the legislation and dissolved oxygen (10\%) below that allowed. It was concluded that the analyzed waters are unfit for human consumption, the wells must be physical protected, disinfected with chlorine and monitored periodically.
\end{abstract}

Keywords: Wells. Coliforms. Water resources. Potability.

\section{INTRODUÇÃO}

Segundo Sperling (2005) os recursos naturais são utilizados para diferentes finalidades em todo o mundo, desde o abastecimento doméstico, agrí́cola e industrial, geração de energia, navegação até uso paisagístico ou de recreação. A água é um recurso natural, finito e dotado de bem econômico sendo essencial para qualquer forma de vida (BRASIL, 1997; CRUZ, 2009). Atualmente, os dados da ONU, afirmam que mais da metade dos rios do mundo estão contaminados. Essa contaminação é proveniente de diferentes fontes, principalmente, destinação incorreta de dejetos de esgoto doméstico, efluentes industriais, agrotóxicos e dejetos de animais (Organização das Nações Unidas, 2010). No meio rural, as causas de contaminação dos recursos hídricos estão, também, relacionadas às atividades agrícolas, sendo, necessário a análise e o monitoramento das fontes de abastecimento para fins de preservação ambiental e zelo pela saúde da população consumidora (LOBO; CALLEGARO, 2000).

No meio rural e em áreas onde não há abastecimento de rede pública, devido ao baixo custo e facilidade de perfuração, a captação de água provêm do aquífero livre, embora possa estar vulnerável à contaminação, o abastecimento de água é feito através da utilização de poços rasos ou nascentes (FOSTER, 1993; SILVA, 1999). Segundo Valias et al. (2002) as áreas rurais que utilizam os poços como fonte para abastecimento humano, estão susceptíveis à contaminação. Isso ocorre devido à deposição diária de resíduo orgânico animal no solo, favorecendo o risco da contaminação durante o processo de captação ou de seu trajeto até o ponto de consumo, principalmente se as áreas de abastecimento estiverem próximas a locais de descarte dos dejetos humanos e de animais.

Os parâmetros físico-químicos e microbiológicos com seus respectivos valores de referências estão descritos na Portaria do Ministério da Saúde no. 2.914/11 e na 
Resolução 357/05 do Conselho Nacional de Meio Ambiente (CONAMA) que dispõe sobre a classificação e diretrizes ambientais para o enquadramento dos corpos de água superficiais, bem como estabelece as condições e os padrões de lançamento de efluentes (BRASIL, 2011). Além disso, o conjunto de parâmetros para o enquadramento dos corpos hídricos brasileiros é uma excelente ferramenta para o monitoramento da qualidade da água e referência na gestão dos recursos hídricos (BRASIL, 2005).

Estudos propostos por Silva e Araújo (2003) e Marques et al. (2010), discorrem sobre como as substâncias químicas, as alterações físicas e os agentes patógenos impactam na qualidade da água destinada ao consumo. Os parâmetros físico-químicos e microbiológicos são responsáveis por indicar o nível da qualidade em um corpo hídrico e quais são as medidas que devem ser tomadas a fim de manter ou implantar ações de gestão e monitoramento para garantir a qualidade da água consumida (MISRA, 1975; GONÇALVES, 2009).

Uma vez que os poços próprios naturais são as principais fontes fornecedoras de água para a população no meio rural ou em áreas onde não há abastecimento público, torna-se imprescindível verificar a qualidade da água e protegê-la de qualquer tipo de contaminação, bem como obter dados para efetiva gestão.

O município de Encantado, conforme dados da administração municipal, possui atividade comercial diversificada, com predominância de empreendedores locais (BRASIL, 2015). O setor comercial representa mais de $20 \%$ do movimento econômico, absorvendo 68\% da mão-de-obra. Destaque para as empresas na produção e exportação de erva-mate, de embutidos e do ramo de higiene e limpeza. Além da área rural que subsidia o município com atividade de agricultura e pecuária.

O presente estudo objetivou realizar um diagnóstico da qualidade da água de poços rasos próprios em relação aos parâmetros físico-químicos e microbiológico em 10 poços utilizados para múltiplos usos no município de Encantado, pertencente à região do Vale do Taquari-RS.

\section{MATERIAL E MÉTODOS}

\section{Área do estudo}

O estudo foi realizado no município de Encantado (FIGURA 1) que está localizado a $144 \mathrm{~km}$ da capital, Porto Alegre, pertencente à Mesorregião do Centro Oriental RioGrandense, apresentando área total de $139,160 \mathrm{~km}^{2}$ e população de 21.750 habitantes (BRASIL, 2015). 
Figura 1: Localização do Município de Encantado no Vale do Taquari, RS

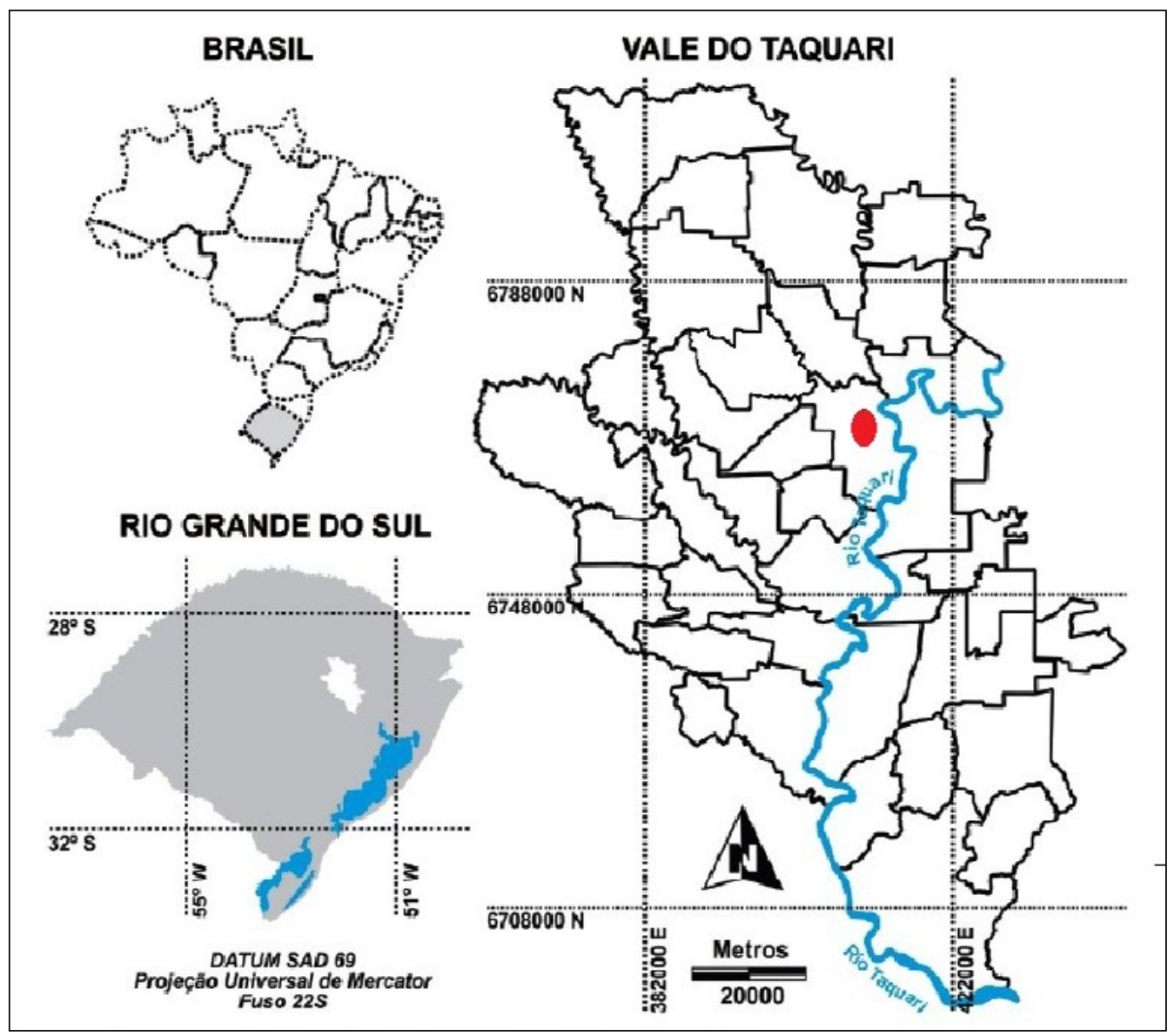

Fonte: Adaptado de Périco et al. (2012).

Para o desenvolvimento do estudo foram selecionados dez poços próprios da zona rural e urbana do município por meio da parceria da Prefeitura Municipal, buscando por residências que utilizassem poços próprios para abastecimento humano, dessedentação animal e outros usos.

A partir de um agendamento foram realizadas atividades in loco nas residências, esclarecendo sobre objetivo do estudo, bem como o procedimento para coleta e diagnóstico da água consumida pelos moradores (FIGURA 2). Durante o processo da coleta foram anotadas observações que caracterizassem o local: temperatura ambiente, isolamento do poço, conservação do poço, finalidade da água, a modificação do ambiente em torno deles, se houveram melhorias realizadas pelos proprietários, ou piora das condições de manutenção. 
Figura 2: Dados de coleta de água enumerados do ponto 1 ao 10 no município de Encantado-RS

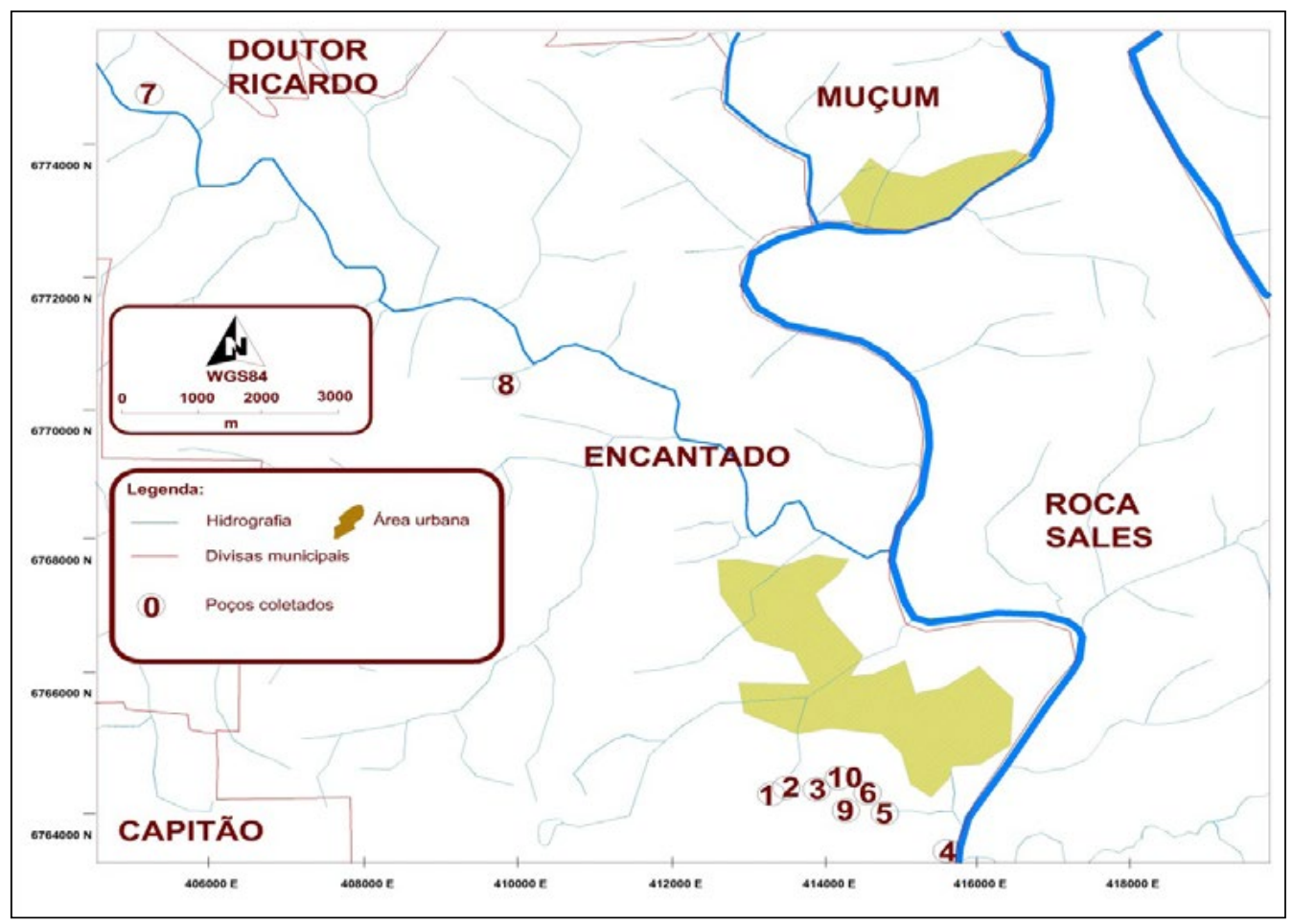

Fonte: Os autores.

\section{Coleta das amostras}

As coletas de água foram realizadas no dia 12 de agosto de 2015, período de inverno, porém em dia seco, sem período de chuvas em dias anteriores. Por meio de atividades in loco com o proprietário foi realizado o levantamento de algumas informações: a) Origem da água utilizada no abastecimento humano; b) Se há tratamento da água. Se sim, qual. c) Caracterização do local onde estão os poços; d) Utilização da água.

$\mathrm{Na}$ sequência, foi coletada uma única amostra de água do poço em cada residência, sendo que, os passos para a realização da coleta basearam-se na metodologia proposta pelo do Manual Prático de Análise de Água (FUNASA, 2009) para os parâmetros físico-químicos e microbiológicos. As amostras foram armazenadas em frascos de vidros $(500 \mathrm{ml})$ autoclavados, vedados com papel alumínio na tampa. Foram utilizados frascos plásticos estéreis tiossulfato de sódio a $10 \%$ de $120 \mathrm{~mL}$ para coletar amostra de água quando a mesma possuir qualquer tratamento (análise dos parâmetros microbiológicos). Os valores das análises de água foram anotados na caderneta de campo.

As coletas foram realizadas em dez poços de diferentes localidades, durante a coleta foram registrados os dados geográficos, utilizando GPS Garmin Dakota 20. 
As coletas foram executadas na residência mais próxima ao poço natural da qual as águas provinham. No local da coleta além das anotações realizadas foram analisados in loco, os seguintes parâmetros: temperatura ambiente, temperatura da água e oxigênio dissolvido. Após a identificação dos frascos, os mesmos foram acondicionados em caixas térmicas, com gelo em gel, em temperatura adequada $\left(3^{\circ} \mathrm{C}\right.$ a $\left.10^{\circ} \mathrm{C}\right)$ e são transportados até o laboratório de Química da Univates para proceder as demais análises.

\section{Análises Microbiológicas}

Para realizar as análises microbiológicas utilizou-se o método de tubos múltiplos, usando separadamente caldo lactosado e de lauril, com alíquotas de $100 \mathrm{ml}$ da amostra, conforme descrito pelo Standard Methods for Water and Wastewater Examination (AMERICAN, 1992).

\section{Análises Físico-químicas}

Para cada amostra coletada analisou-se: temperatura, turbidez, colorimetria, $\mathrm{pH}$, condutividade, dureza, fósforo total, carbono orgânico, carbono inorgânico, carbono total, nitrogênio, sólidos totais suspensos. Foram também analisados os íons Fluoreto, Cloreto, Nitrato e Sulfato. Cada parâmetro foi analisado em equipamento específico (TABELA 1), para a determinação da dureza utilizou-se o método de titulação (AMERICAN, 1992; MACÊDO, 2001).

Tabela 1 - Parâmetros físico-químicos analisados e respectivas marcas e metodologias utilizada

\begin{tabular}{l|c|c}
\hline Parâmetros & Equipamento & Marca/Modelo \\
\hline Carbono total $(\mathrm{mg} / \mathrm{L})$ & HPLC e CG & SHIMADZU \\
\hline Carbono organico total $(\mathrm{mg} / \mathrm{L})$ & HPLC e CG & SHIMADZU \\
\hline Cor & Colorímetro & Digimed/ DM-COR \\
\hline Dureza & Complexiometria com & - \\
\hline Eletrocondutividade $(\mu \mathrm{s})$ & EDTA & Digimed/DM-32 \\
\hline Nitrogênio total $(\mathrm{mg} / \mathrm{L})$ & HPLC e CG & SHIMADZU \\
\hline $\mathrm{O}_{2}$ dissolvido & Oxímetro & Digimed/DM-4P \\
\hline $\mathrm{pH}$ & pHmetro & Digimed/DM-20 \\
\hline Temperatura Ambiente & Termômetro de $0^{\circ}$ a $60^{\circ}$ & Incoterm \\
\hline Turbidez $(\mathrm{NTU})$ & Turbidímetro & Digimed/DM-TU \\
\hline
\end{tabular}


Os dados obtidos foram tabulados em planilhas no software Microsoft Excel 2010. Os dados físico-químicos da água foram analisados mediante o uso de média, desviopadrão e correlação linear de Pearson, obtidos no software Microsoft Excel 2010. Para a verificação da potabilidade da água foram comparados os parâmetros obtidos com as definições da Portaria do Ministério da Saúde no 2.914 de 12/12/2011 (BRASIL, 2011) e CONAMA 357/2005.

\section{RESULTADOS E DISCUSSÕES}

A partir das coletas de águas obtidas nos poços do município de Encantado (FIGURA 3), constatou-se que os poços analisados segundo a Associação Brasileira de Águas Subterrânea (ABAS, 2017) são considerados rasos, pois estes possuem profundidades geralmente de até 20 metros e as amostras não passaram de 4 metros de profundidade.

Figura 3: Tipos de poços utilizados no Município de Encantado-RS

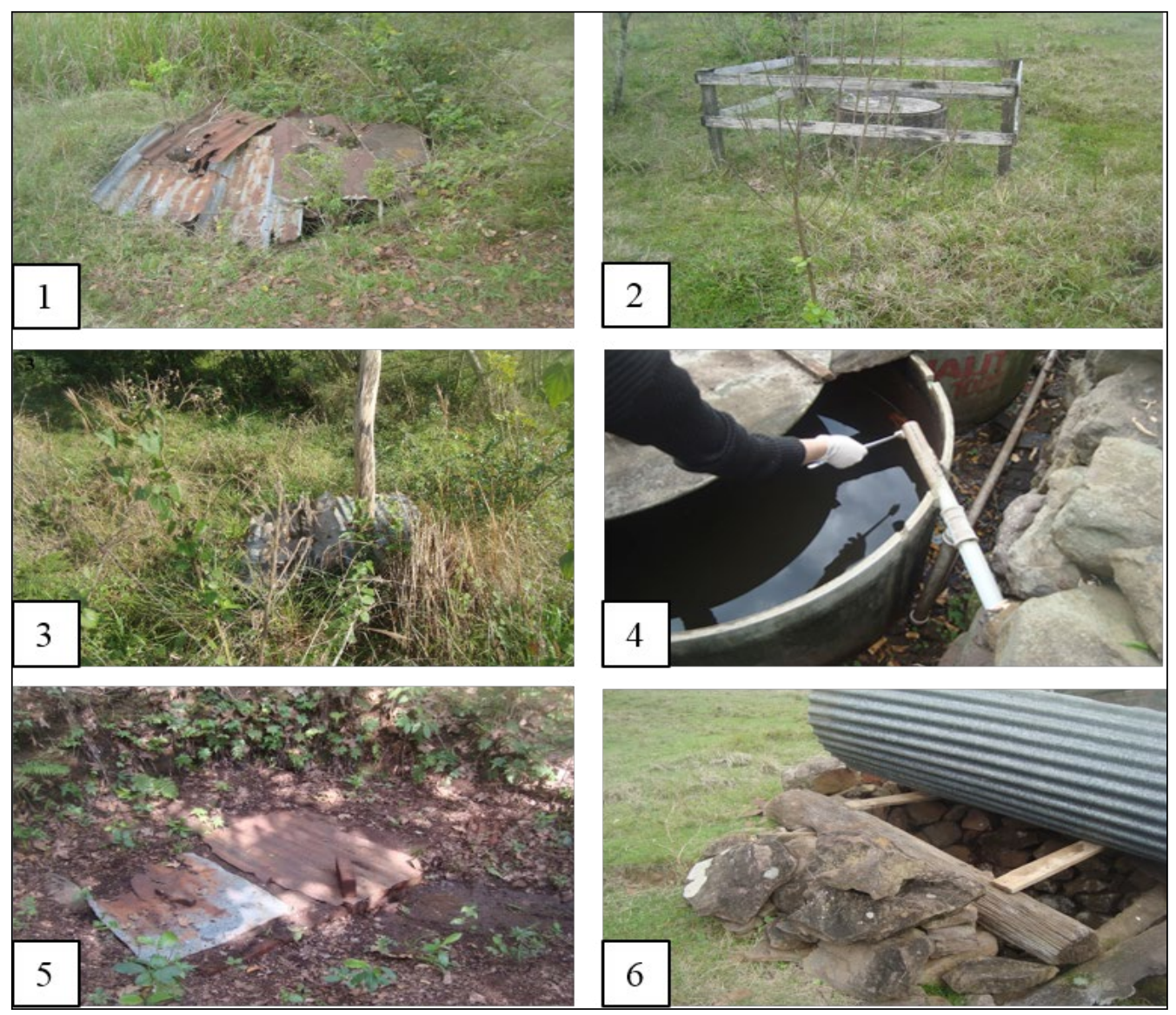




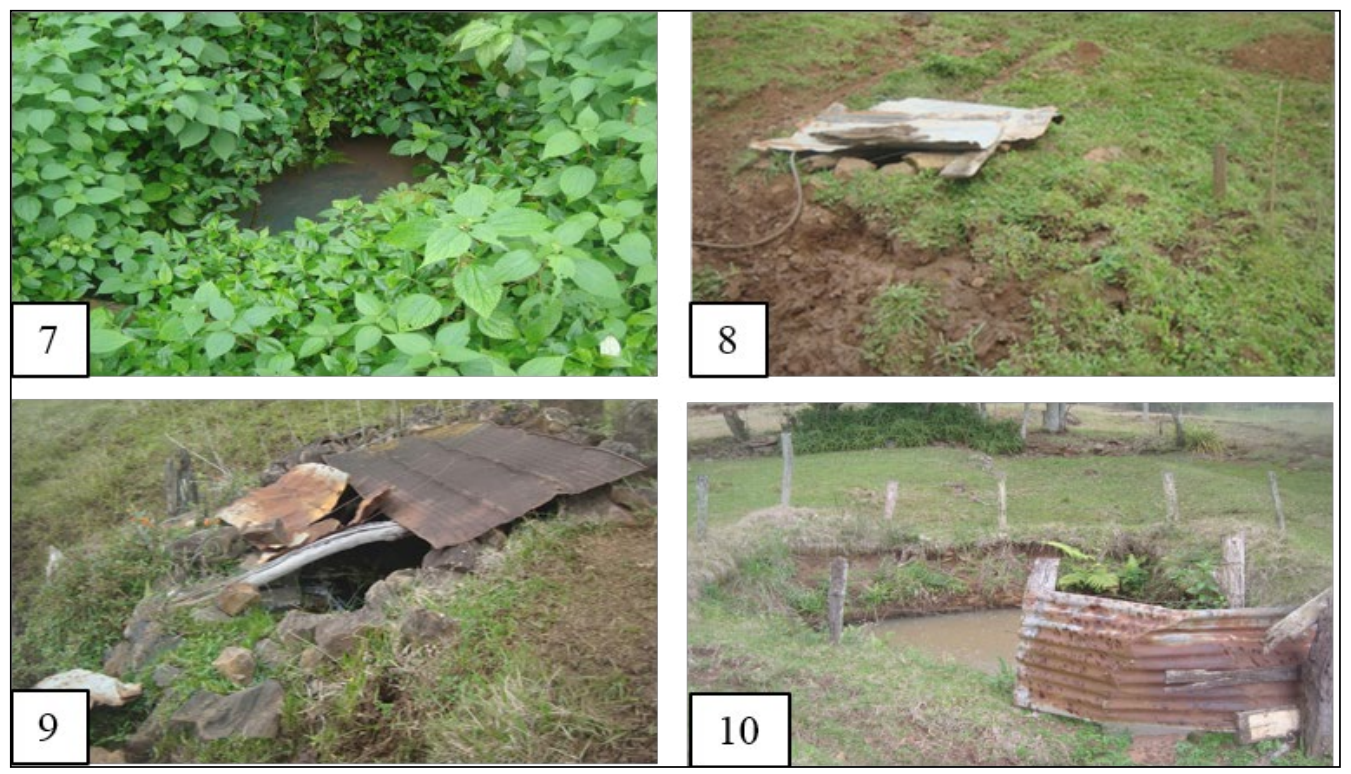

Fonte: Autores

Destaca-se que os poços são utilizados para diversas finalidades como o uso para o consumo humano e animal, uso doméstico entre outros. Os poços um, dois, três, seis, sete e nove são usados para consumo humano, os poços oito e dez para dessedentação animal, o poço quatro uso em hortaliças e o poço cinco uso doméstico.

Em 70\% das amostras, os poços estão localizados em áreas de potreiro com presença do gado, além disso, os poços 2, 8, 9 e 10 possuem isolamento. Segundo Foster e Hirata (1988) com a existência da proteção, a vulnerabilidade de agentes poluidores ou fatores que possam contaminar a água é menor. $O$ poço sete é caracterizado pela presença de vegetação, o poço quatro é de uso exclusivo para a irrigação em horta, a fonte encontrase próxima ao reservatório, estando em bom estado de preservação, com construção em alvenaria e tampa especial, consequentemente evitando contaminações.

Quanto aos valores para coliformes termotolerantes (Escherichia coli), constataramse resultados positivos em todas as amostras analisadas. O Número Mais Provável (NMP) de coliformes totais e termotolerantes estão expressos na Tabela 2. 
Tabela 2 - Características microbiológicas da água de poços próprios no município de Encantado-RS

\begin{tabular}{l|c|c}
\hline Amostra & Coliformes Totais (NMP*) & Termo tolerantes (NMP) \\
\hline Poço1 & 20 & 15 \\
\hline Poço 2 & 460 & 11 \\
\hline Poço 3 & 15 & 9,2 \\
\hline Poço 4 & 21 & 7,4 \\
\hline Poço 5 & 15 & 3,6 \\
\hline Poço 6 & 7,4 & 3,6 \\
\hline Poço 7 & 93 & 21 \\
\hline Poço 8 & 36 & 11 \\
\hline Poço 9 & 11 & 3 \\
\hline Poço 10 & 21 & 11 \\
\hline
\end{tabular}

*Número mais provável em $100 \mathrm{ml}^{-1}$

A Portaria do Ministério da Saúde 2914/11 regulamenta os padrões de portabilidade da água de consumo humano, assim, exigindo ausência de coliformes termotolerantes em $100 \mathrm{ml}^{-1}$ (BRASIL, 2011).

Os poços são utilizados para diversas finalidades e o que mais chama a atenção é haver presença de coliformes termotolerantes nas amostras utilizadas para abastecimento humano (60\% das propriedades/poços 1, 2, 3, 6, 7 e 9), além disso, esta é a única ou principal fonte de abastecimento nas residências. Tais resultados, são semelhantes aos estudos de Capp et al. (2012) e Burgos et al. (2014), ambos focados em poços rasos de outras regiões. Nesses estudos, as amostras de água dos poços encontraram-se com altos valores para coliformes, estando, portanto, impróprias para o consumo.

Garantir a potabilidade da água depende de uma visão sistêmica, sendo necessário levar em conta o manancial e o percurso até o consumo (HELLER; PÁDUA, 2006). O cloro é uma das técnicas mais antigas e de fácil utilização para o tratamento de água, sendo utilizado até os dias de hoje. Estudos garantem que a partir do momento que passou a ser utilizado como tratamento em redes de abastecimento, houve redução das doenças causadas pela água contaminada (SABESP, 2014).

As demais residências (40\%) utilizam a água para irrigação na horta (poço 4, representando 10\%), uso doméstico (poço 5, representando 10\%) e dessedentação animal (poço 8 e 10, representando 20\%). A Resolução CONAMA 357/05, classe 3, permite que a água apresente até 1.000 coliformes termotolerantes $(E$. coli) em 100 $\mathrm{mL}$, quando destinada à dessedentação animal (BRASIL, 2005), se utilizarmos esses 
valores de referência, os poços 8 e 10 estão de acordo com a lei, podendo ser utilizados para essa finalidade.

Os resultados dos parâmetros físico-químicos obtidos a partir das análises estão expressos na Tabela 3.

Tabela 3. Valores de tendência central e dispersão das variáveis analisadas nos dez poços monitorados no município de Encantado-RS

\begin{tabular}{|c|c|c|c|c|c|c|c|c|c|c|c|}
\hline Parâmetros & $\underset{\left(\mathrm{mg} \mathrm{L}^{-1}\right)}{\mathbf{C T}}$ & $\underset{\left(m g L^{-1}\right)}{\operatorname{COT}}$ & $\begin{array}{c}\text { Cor } \\
(\mathrm{uH})\end{array}$ & $\begin{array}{l}\text { Dureza } \\
\left(\mathrm{mg} \mathrm{L}^{-1)}\right.\end{array}$ & $\operatorname{Ec}(\mu \mathrm{s})$ & $\begin{array}{l}\text { NT } \\
(\mathrm{mg} \\
\left.\mathrm{L}^{-1}\right) \\
\end{array}$ & $\begin{array}{l}\text { OD } \\
(\mathbf{m g} \\
\left.\mathrm{L}^{-1}\right) \\
\end{array}$ & $\mathrm{pH}$ & $\begin{array}{c}\mathrm{T} \\
\text { (NTU) }\end{array}$ & $\begin{array}{l}\mathrm{T}^{\circ} \mathrm{C} \\
\mathrm{H}_{2} \mathrm{O}\end{array}$ & $\mathbf{T}^{\circ} \mathrm{C}$ \\
\hline Poço 1 & 23,04 & 3,07 & 38,9 & 61,61 & 133,63 & 0 & 12,2 & 7,78 & 21,3 & 16 & 11 \\
\hline Poço 2 & 21,31 & 3,03 & 33,2 & 70,7 & 140,14 & 0 & 8,3 & 7,59 & 17,71 & 16 & 16 \\
\hline Poço 3 & 28,23 & 2,07 & 11,5 & 86,86 & 183,43 & 0 & 7,3 & 7,58 & 7,65 & 15 & 16 \\
\hline Poço 4 & 43,41 & 2,00 & 4,1 & 135,34 & 314,3 & 5 & 6 & 7,62 & 1,03 & 21,5 & 18 \\
\hline Poço 5 & 25,29 & 4,22 & 141 & 72,72 & 132,92 & 0 & 8,5 & 7,44 & 39,1 & 16,5 & 18 \\
\hline Poço 6 & 32,06 & 1,77 & 7,6 & 92,92 & 183,84 & 1 & 9,2 & 7,96 & 9,39 & 19 & 20,5 \\
\hline Poço 7 & 21,92 & 2,11 & 26,9 & 58,58 & 113,68 & 2 & 6,9 & 7,87 & 24,1 & 17 & 18,5 \\
\hline Poço 8 & 27,33 & 1,77 & 1,5 & 94,94 & 224,2 & 0 & 6,9 & 7,04 & 2,14 & 20 & 20,5 \\
\hline Poço 9 & 35,45 & 1,71 & 5,7 & 119,18 & 265,01 & 0 & 6,6 & 7,25 & 8,75 & 19,8 & 21,5 \\
\hline Poço 10 & 22,21 & 2,57 & 115 & 52,52 & 101,12 & 0 & 5,6 & 7,28 & 31,6 & 18 & 17,5 \\
\hline Min-Max & $21,31-43,41$ & $7,71-4,22$ & $1,5-141$ & $52,52-135,3$ & $101,1-314,3$ & $0-4,72$ & $5,6-12,2$ & 7,04-7,96 & $1,03-39,1$ & $15-21,5$ & $11-21,5$ \\
\hline Média & 28,02 & 2,43 & 38,54 & 84,53 & 179,23 & 0,85 & 7,75 & 7,54 & 12,71 & 17,88 & 17,75 \\
\hline
\end{tabular}

Valores máximos, mínimos e média. CT- Carbono total; COT - Carbono orgânico total; Cor; Dureza; Ec- Eletrocondutividade, NT- Nitrogênio total; OD- Oxigênio dissolvido; pHPotencial Hidrogeniônico; $\mathrm{T}^{\circ} \mathrm{C} \mathrm{H}_{2} \mathrm{O}$ - Temperatura da água, $\mathrm{T}^{\circ} \mathrm{C}$ - Temperatura ambiente; $\mathrm{T}$ Turbidez.

Fonte: os autores.

De acordo com os resultados obtidos, segundo a Portaria 2911/2011 do Ministério da Saúde, a água potável deve estar em conformidade com o padrão de aceitação para consumo humano. Para tanto são estabelecidos valor máximo permitido para a dureza $(500 \mathrm{mg} / \mathrm{L})$, cor $(15 \mathrm{uH})$, turbidez (5 NTU) e $\mathrm{pH}(6,0$ a 9,5). (BRASIL, 2011). No presente estudo, todas as amostras estiveram em conformidade com os valores de dureza apresentando valores entre 101,1-314,3 e pH valores variados entre 7,04 e 7,96 (TABELA 3).

A turbidez apresentou resultados elevados em $80 \%$ das amostras e a cor acima do estabelecido em 50\% das amostras. Para Alves (2010) a turbidez indica a presença de partículas em suspensão na água, além disso, altas concentrações de matéria orgânica e micro-organismos formam a matéria em suspensão nas águas naturais, deixando- 
as turva. Períodos de chuva nas quais quantidades maiores de solo são carreadas para lagos e rios favorece o aumento da turbidez (LENZI; FAVERO; LUCHESE, 2009). Enquanto que, o parâmetro cor, segundo Libânio (2010) está relacionado à decomposição de matéria orgânica de origem vegetal e do metabolismo de organismos presentes no solo e de atividades antrópicas.

Observou-se ainda que, o parâmetro Carbono Total (CT) apresentou-se semelhante em todos os poços, com a média $28,02 \pm 7,12 \mathrm{mg} \mathrm{L}^{-1}$. Sendo que, o Carbono Orgânico Total (COT) apresentou valores baixos. Apenas os poços 4, 6 e 9 apresentaram maiores valores de concentração de $\mathrm{CT}$, porém destes, apenas $2,00 \mathrm{mgL}$ ${ }^{1}, 1,77 \mathrm{~m} \mathrm{gL}^{-1}$ e $1,71 \mathrm{mgL}^{-1}$ respectivamente representam os valores COT, ou seja, a maior parte do CT é formado por carbono inorgânico. Além disso, os valores de NT foram diretamente proporcionais a quantidade de CT $\left(r^{2}=62,21 \% ; p=0,0548\right)$ em todos os poços, sendo que a concentração TN não apresentou variação, e apenas os poços 4,6 e 7, respectivamente, apresentaram $5 \mathrm{mgL}^{-1}, 1 \mathrm{mgL}^{-1}$ e $2 \mathrm{mgL}^{-1}$.

Estes dados indicam que a matéria orgânica apresenta pouca variação de um poço para o outro, isto pode estar relacionado ao fato de estar, localizados em áreas próximas, portanto, há pouca variação de um poço para outro em relação à diluição das águas pelas chuvas. Outro fator pode estar relacionado a questão da luminosidade, pois, ambos os poços estavam cobertos, recebendo pouca luminosidade e consequentemente, apresentaram baixos valores de COT, tais resultados encontram-se mais concentrados devido ao clima favorecer a dissolução do $\mathrm{CO}_{2}$ atmosférico na água.

O oxigênio dissolvido (OD), não apresenta VMP na Portaria do Ministério da Saúde, mas se comparados aos VMP estipulados pela Resolução CONAMA 357/2005, $90 \%$ das amostras estão de acordo com os valores estabelecidos. Os valores de OD não apresentaram correlação significante em relação à temperatura da água $\left(r^{2}=-47,15 \%\right.$; $\mathrm{p}=0,1689)$, apenas o poço 10 apresentou valores de OD abaixo do recomendado (TABELA 3), isso pode estar relacionado à falta de movimentação ressurgente da água.

A condutividade elétrica da água, segundo Libânio (2010) está relacionada ao teor de salinidade, característica importante a mananciais subterrâneos e águas superficiais próximas ao litoral. Alves (2010) argumenta que a medida que sólidos dissolvidos são adicionados, a condutividade da água se eleva e valores altos podem indicar características corrosivas da água. Os resultados encontrados a partir das análises dos poços apresentaram valores entre $101,1 \mu \mathrm{S} \mathrm{cm} \mathrm{cm}^{-1} \mathrm{a} 314,3 \mu \mathrm{S} \mathrm{cm}^{-1}$ (TABELA 3) indicando que há baixa concentração de sais e que estes limites são aceitáveis de acordo com Alves (2010).

\section{CONSIDERAÇÕES FINAIS}

As análises físico-químicas estavam de acordo com os padrões de potabilidade definidos pela Portaria n ${ }^{\circ}$ 2914/2011 do Ministério da Saúde, exceto para cor e turbidez, 
na qual alguns poços apresentaram valores superiores aos recomendados pela legislação. Enquanto que as análises microbiológicas apresentaram valores em desacordo com os valores máximos permitidos em relação ao padrão de potabilidade. Dessa forma, essas águas não devem ser utilizadas para o consumo humano. Devem ser tomadas medidas para redução do número de coliformes termotolerantes, de forma que atenda à legislação vigente.

Sugere-se proteger os poços por meio de revestimento das bordas, paredes e tampas com alvenaria ou concreto, bem como manter afastados do local, animais domésticos, protegendo-se o perímetro em torno dos poços e não utilizar adubos orgânicos de origem animal próximo ao recurso hídrico. Dessa forma, minimiza-se a contaminação por microrganismos.

Além disso, é importante que haja desinfecção das águas com a utilização de cloro antes do consumo e o monitoramento constante dessas fontes, observando se a contaminação se mantém estável ou se tende a diminuir.

\section{REFERÊNCIAS}

ABAS. Associação Brasileira de Águas Subterrânea. Disponível em: <http://www.abas.org/ educacao_pocos.php>. Acesso em: fevereiro, 2017.

ALVES, Célia. Tratamento de águas de abastecimento. 3. ed. Porto: Publindústria, 2010.

AMERICAN PUBLIC HEALTH ASSOCIATION. Water pollution control federation. Standard methods for the examination of water and wastewater, v. 19, 1992.

BRASIL. Lei No 9.433 de 08 de janeiro de 1997. Dispõe sobre a Política Nacional de Recursos Hídricos

BRASIL, MINISTÉRIO DA SAÚDE. Portaria n. 2914 de 12/12/2011. Dispõe sobre os procedimentos de controle e de vigilância da qualidade da água para consumo humano e seu padrão de potabilidade. Diário Oficial da União, 2011.

BRASIL. Instituto Brasileiro de Geografia e Estatística - IBGE. Cidade de Encantado Estado do Rio Grande do Sul. Disponível em: <http://www.cidades.ibge.gov.br/xtras/perfil. php?lang=\&codmun=430680\&search=rio-grande-do-sul|encantad $>$. Acesso em: Março, 2015.

BRASIL. Resolução $N^{\circ}$ 357, de 17 de março de 2005. Dispõe sobre a classificação dos corpos de água e diretrizes ambientais para seu enquadramento, bem como estabelece as condições e padrões de lançamento de efluentes, e dá outras providências. Brasília, DF, 2005.

BURGOS, Tatiane das Neves et al. Água de consumo humano proveniente de poços rasos como fator de risco de doenças de veiculação hídrica. Rev. Ciênc. Saúde, São Luís, v. 16, n. 1, p.34-38, 2014.

CAPP, Nanci et al. Qualidade da água e fatores de contaminação de poços rasos na área urbana de Anastácio (MS). Geografia Ensino \& Pesquisa, Cascavel, v. 16, n. 3, p.77-92, 2012 . 
CRUZ, J.T. A Importância da Água no Meio Ambiente. São Jose dos Pinhais, 2009.

FOSTER, S. Determinação do risco de contaminação das águas subterrâneas: um método baseado em dados existentes. Instituto Geológico, São Paulo. 1993.

FOSTER, S; HIRATA, R. Groundwater pollution risk evaluation: the methodology using available data. Lima, CEPIS, 1988. 78p.

FUNASA, Fundação Nacional de Saúde. Manual prático de análise de água, Brasília, 2004.

GONÇALVES, E. M. Avaliação da Qualidade da água do Rio Uberabinha Uberlândia - MG. 2009. 159 f. Dissertação (Mestrado em Ciências) - Universidade Federal do Rio de Janeiro, Rio de Janeiro. 2009.

HELLER, L; PÁDUA, V.L. Abastecimento de água para consumo humano. 1.ed. Minas Gerais: Editora UFMG, 2006. 859 p.

LENZI, E.; FAVERO, L. O. B.; LUCHESE, E. B.. Introdução à química da água: ciência, vida e sobrevivência. Rio de Janeiro: LTC, 2009.

LIBÂNIO, M. Fundamentos de qualidade e tratamento de água. 3. ed. Campinas: Átomo, 2010.

LOBO, E. A., CALLEGARO, V. L. Avaliação da qualidade de águas doces continentais com base em algas diatomáceas epilíticas: enfoque metodológico. In: TUCCI, C. E. M.; MARQUES, D. M. (Org.). Avaliação e Controle da Drenagem Urbana. Porto Alegre: Ed. Universidade/UFRGS, p. 277-300. 2000.

MACÊDO, Jorge Antonio Barros de. Águas e águas: métodos laboratoriais de analises físicoquímicas e microbiológicas. Juiz de Fora: Jorge Macedo, 2001.

MARQUES, F.C. et al. Qualidade das Águas Subterrâneas da Área Urbana no Município de Santa Helena (Ma). Anais. Congresso Brasileiro de Águas Subterrâneas, 16 e Encontro Nacional de Perfuradores de Poços, 17. 2010.

MISRA, K.K. Safe water in rural reas. Int J Health Educ. v. 18, p. 53-9. 1975

PÉRICO, E; CEMIN, G; MOHR, L.R.S. Fisiografia da bacia hidrográfica do rio Forqueta, RS, sul do Brasil. Scientia Plena, v.8, n. 9, p. 1-9, 2012.

SABESP - Saneamento Básico de São Paulo. Tratamento de Água. Disponível em: <http:// site.sabesp.com.br/site/interna/Default.aspx?secaoId=491>. Acesso em: 01 ago. 2014.

SILVA R.C. ASSIS DA. Abrindo mão do direito ao consumo da água tratada: Feira de Santana - BA. Monografia apresentada ao curso de especialização em Direito Sanitário. Departamento de Saúde, Universidade Estadual de Feira de Santana. 1999.

SILVA, R.C.A; ARAÚJO, T.M. Qualidade da água do manancial subterrâneo em áreas urbanas de Feira de Santana (BA). Ciênc Saúde Colet, v. 8, n. 4, p.1019-1028, 2003,

VALIAS, A. P. G. S; ROQUETO, M. A; HORNINK, D. G; KOROIVA, E. H.; Avaliação da qualidade microbiológica de água de poços rasos e de nascentes de propriedades rurais do município de São José da Boa Vista- São Paulo. Ciências Veterinárias e Zoologia UNIPAR, v.5, n.1. 2002. 